\title{
Pemanfaatan Batu Sungai Apanang Kecamatan Marioriwawo Kabupaten Soppeng Sebagai Agregat Pada Campuran AC-BC
}

\author{
Randi Frimus Madallo *1, Robert Mangontan *2, Alpius ${ }^{* 3}$ \\ *1 Mahasiswa Program Studi Teknik Sipil, Universitas Kristen Indonesia Paulus Makassar, \\ Indonesia randifrimusmadallo@gmail.com \\ *2,3 Dosen Program Studi Teknik Sipil, Universitas Kristen Indonesia Paulus Makassar, Indonesia ${ }^{2}$ \\ robertm@ukipaulus.ac.id dan alpiusnini@gmail.com
}

Corresponding Author: alpiusnini@gmail.com

\begin{abstract}
Abstrak
Pembangunan konstruksi jalan pada umumnya menggunakan bahan yang berasal dari alam dan sampai saat ini hampir semua pekerjaan infrastruktur jalan mendatangkan material dari tempat lain. Penelitian ini bertujuan untuk menguji karakteristik campuran Asphalt Concrete - Binder Course menggunakan agregat Sungai Apanang berdasarkan pengujian Laboratorium. Metode pengujian yang digunakan yaitu uji marshall konvensional yang digunakan untuk mendapatkan nilai KAO, setelah itu dilakukan pembuatan benda uji untuk KAO untuk mendapatkan Stabilitas Marshall Sisa. Dari hasil pengujian menunjukkan karakteristik agregat Sungai Apanang Kabupaten Soppeng Memenuhi Standar Spesifikasi Bina Marga sebagai bahan untuk campuran Asphalt Concrete - Binder Course. Sesuai dengan hasil pengujian Marshall konvensional diperoleh nilai VIM, VMA, stabilitas, flow dan VFB memenuhi Spesifikasi Umum Bina Marga Tahun 2018. Dan dari hasil pengujian Marshall Immersion didapatkan nilai sebesar 92,59\% dengan kadar aspal 6,00\% serta telah memenuhi Spesifikasi Umum Bina Marga Tahun 2018.
\end{abstract}

Kata kunci: Karakteristik Agregat, AC-BC, Marshall Test.

\begin{abstract}
Road construction generally uses materials that come from nature and until now almost all road infrastructure works have brought in materials from other places. This study was intended to test the characteristics of the AC-BC mixture using the Apanang River aggregate based on laboratory testing. The test method used is the conventional marshall test which is used to obtain the KAO value, after that, the test object is made for the KAO to obtain the Marshall Residual Stability. The test results show that the aggregate characteristics of the Apanang River, Soppeng Regency, meet the Bina Marga Specifications standard as an ingredient for the AC-BC mixture. In accordance with the results of the conventional Marshall test, the values of VIM, VMA, stability, flow and VFB meet the General Specifications of Highways in 2018. And from the results of the Marshall Immersion test, a value of $92.59 \%$ is obtained with an asphalt content of $6.00 \%$ and has met the General Specifications. Highways in 2018.Keywords: Aggregate Characteristics, AC-BC, Marshall Test.
\end{abstract}




\section{PENDAHULUAN}

Material alam seperti batu dan pasir umumnya digunakan dalam konstruksi perkerasan jalan. Material ini digunakan sebagai lapisan pondasi jalan tanpa bahan pengikat atau dengan penambahan bahan pengikat pada campuran aspal beton. Khususnya perkerasan lentur terdiri dari agregat kasar, agregat halus, aspal, dan filler. Merupakan salah satu jenis perkerasan lentur yang paling banyak digunakan di Indonesia saat ini. Pada struktur perkerasan lentur banyak aspek yang harus ditinjau, salah satunya adalah material yang akan digunakan, metode pencampuran dan pemadatanya [1].

Sampai saat ini hampir semua pekerjaan infrastruktur jalan mendatangkan material dari tempat lain, yang tentunya membutuhkan biaya yang lebih mahal dan waktu yang akan lebih lama [2]. Oleh sebab itu untuk mengurangi ketergantungan terhadap material yang didapatkan dari tempat lain khususnya untuk infrastruktur jalan maka perlu dicarikan alternatif material lokal yang ketersediaan materialnya dekat dengan lokasi pekerjaan jalan.

Material di Sungai Apanang yang terletak di Kabupaten Soppeng memiliki luas sungai sekitar 7000 Ha yang memiliki ketersediaan material untuk menunjang pembangunan jalan di kawasan tersebut. Namun agregat pada sungai ini belum dimanfaatkan untuk pembangunan infrastruktur jalan. Oleh karena itu, sangat diperlukan hasil penelitian pada Laboratorium tentang karakteristik agregatnya melalui pengujian marshall. Dari hasil pengujian tersebut kita dapat mengetahui apakah agregat Sungai Apanang dapat dimanfaatkan untuk campuran beraspal dan berdasarkan pada Spesifikasi Umum Bina Marga 2018 [3] [4].

Penelitian mengenai pemanfaatan material lokal yang digunakan untuk lapisan perkerasan jalan sudah banyak dilakukan. Pengujian Karakteristik campuran Laston Lapisan Antara menggunakan Batu Sungai Pucak Kabupaten Maros [5]. Pemanfaatan Limbah Styrofoam Sebagai Bahan Tambah Campuran AC-BC Yang Menggunakan Sungai Bittuang [6]. Pemanfaatan Batu Gunung Bottomale Toraja Utara sebagai Campuran Laston [7]. Penggunaan Agregat Sungai Batu Tiakka' dalan campuran AC-BC [8]. Pemanfaatan Batu Sungai Melli Kecamatan Baebunta Kabupaten Luwu Utara Dalam Campuran AC-WC [9]. Variasi Suhu Pemadatan Campuran AC-WC Menggunakan Batu Sungai Balusu Kabupaten Toraja Utara [10]. Pemanfaatan Batu Gunung Posi’ Padang Balla Kabupaten Mamasa Sebagai Campuran AC-BC [11].

Penelitian ini bertujuan untuk menguji karakteristik campuran Asphalt Concrete - Binder Course menggunakan agregat Sungai Apanang berdasarkan pengujian Laboratorium.

\section{METODOLOGI}

\section{Lokasi Pengambilan Material}

Lokasi pengambilan agregat batu Sungai Apanang ini terletak di Kecamatan Marioriwawo Kabupaten Soppeng berjarak dari pusat kota Soppeng sekitar $45 \mathrm{~km}$ yang memiliki luas wilayah 1,557 km², dapat dilihat pada gambar 1. 


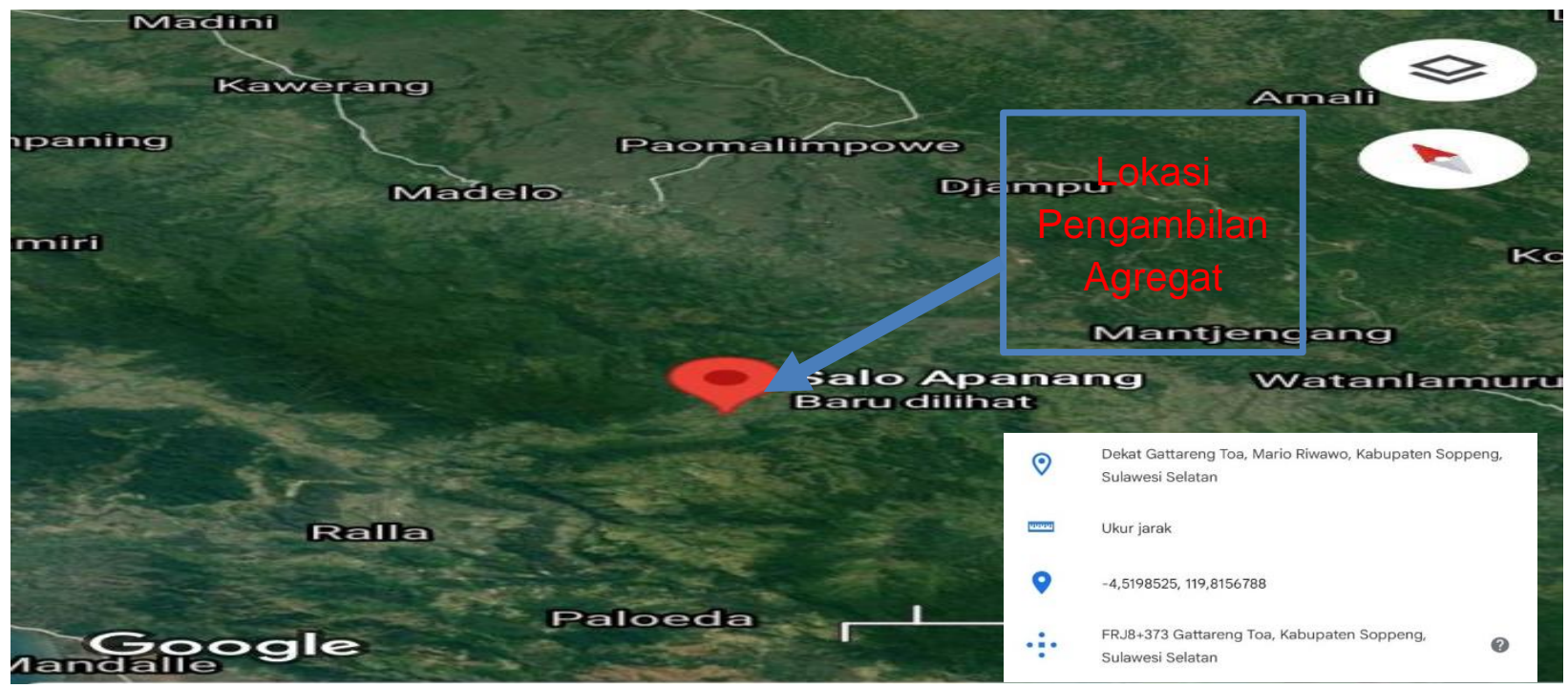

Gambar 1. Lokasi pengambilan agregat

\section{Perancangan Komposisi Lapis Antara (BC)}

Komposisi campuran AC-BC terdiri dari agregat, filler (komponen pengisi), dan bahan pengikat yaitu aspal. Campuran AC-BC yang digunakan didasarkan pada grafik dan metode analisis yaitu berdasarkan tabel batas spesifikasi gradasi campuran, kemudian ditentukan gradasi ideal yaitu nilai rata-rata batas spesifikasi untuk setiap gradasi. Dan kemudian menghitung proporsi masing-masing fraksi, yaitu Persyaratan agregat kasar, agregat halus dalam campuran aspal. Langkah terakhir adalah memasukkan semua hasil gradasi campuran ke dalam grafik gradasi untuk menunjukkan apakah setiap persentase skala gradasi dalam campuran berada dalam rentang skala gradasi yang sesuai dengan spesifikasi. Dengan catatan ukuran dari fraksi tersebut didasari oleh Departemen Pekerjaan Umum, 2018, "Pelaksanaan Lapis Beton Aspal (LASTON) Untuk Jalan Raya".

Tabel 1. Komposisi Pada Campuran Asphalt Concrete - Binder Course

\begin{tabular}{|c|c|c|c|}
\hline \multirow{3}{*}{ No. Ayakan } & \multirow{3}{*}{ Ukuran } & \multicolumn{2}{|c|}{$\begin{array}{c}\text { \% Berat yang Lolos Berbanding Total Agregat pada } \\
\text { Campuran }\end{array}$} \\
\hline & & \multicolumn{2}{|c|}{ Spesifikasi Gradasi ( Asphalt Concrete-Binder Course) } \\
\hline & & Ketentuan Campuran & Gradasi Campuran \\
\hline $1 \frac{1}{2}$ & 37,5 & & \\
\hline 1 & 25 & 100 & 100 \\
\hline $3 / 4$ & 19 & $90-100$ & 95,5 \\
\hline $1 / 2$ & 12,5 & $75-90$ & 82,5 \\
\hline $3 / 8$ & 9,5 & $66-82$ & 74,0 \\
\hline 4 & 4,75 & $46-64$ & 55,0 \\
\hline 8 & 2,36 & $30-49$ & 39,5 \\
\hline 16 & 1,18 & $18-38$ & 28,0 \\
\hline 30 & 0,6 & $12-28$ & 20,0 \\
\hline 50 & 0,3 & $7-20$ & 13,5 \\
\hline 100 & 0,15 & $5-13$ & 9,0 \\
\hline 200 & 0,075 & $4-8$ & 6,0 \\
\hline
\end{tabular}

\section{Perhitungan Kadar Aspal Perkiraan Awal Untuk AC - BC}

Untuk perhitugan kadar aspal awal dalam campuran dapat dihitung dengan rumus: 


$$
\text { Berat Aspal (gr) } \quad=\frac{K A}{100 \%} \mathrm{X} 1200 \mathrm{gr}
$$

Tabel 2. Komposisi Aspal Dalam Campuran Asphalt Concrete - Binder Course

\begin{tabular}{lccccc}
\hline $\begin{array}{l}\text { Kadar aspal } \\
\text { rancangan }(\%)\end{array}$ & 1 & 2 & 3 & 4 & 5 \\
\hline & 5,00 & 5,50 & 6,00 & 6,50 & 7,00 \\
\hline $\begin{array}{l}\text { Kebutuhan } \\
\text { Bitumen (gr) }\end{array}$ & 60 & 66 & 72 & 78 & 84 \\
\hline
\end{tabular}

\section{Persiapan Sampel Asphalt Concrete Binder Course}

Setelah semua bahan yang diperlukan telah melalui pengujian, maka selanjutnya adalah menentukan berapa jumlah sampel yang akan dibuat dan menyiapkan komposisi sesuai desain campuran yang telah direncanakan.

\section{Pemeriksaan/Pengujian Lapis Antara Untuk Tes Marshall Konvensional}

Prinsip dasar pengujian dengan metode Marshall konvensional merupakan pengujian terhadap stabilitas dan kelelehan (flow), yang mengacu pada SNI 06-2489-1991. Dalam hal ini sampel dibuat berdasarkan gradasi agregat campuran yang telah didapat berdasarkan pengujian gradasi dan sesuai dengan standar. Pada alat marshall dilengkapi dengan cincin penguji yang berfungsi untuk mengukur stabilitas campuran, dan pada samping terdapat arloji kelelehan untuk mengukur kelelehan (flow).

\section{Penentuan Nilai KAO Dan Persiapan Sampel Nilai KOA Campuran AC - BC}

Penentuan kadar aspal optimum didapatkan dari sampel yang telah melalui proses pengujian marshall konvensional, dimana hasil pengujian marshall konvensional dianalisis karakteristik marshallnya untuk mendapatkan nilai kadar aspal optimum. Dari nilai kadar aspal optimum kemudian dibuatkan sampel untuk pengujian marshall immersion.

\section{Pemeriksaan SMS (Immersion Test)}

Yang akan diperoleh pada pengujian marshall Immersion adalah Untuk mengetahui ketahanan campuran beraspal terhadap air yang mempunyai temperatur $60^{\circ} \mathrm{C}$ dalam waktu 30 menit untuk rasio stabilitas dan juga 24 jam untuk Pengujian stabilitas Marshall sisa. Pengujian ini mengacu pada SNI 06-2489-1990 sebagai pedoman.

\section{ANALISA DAN PEMBAHASAN}

\section{Karakteristik campuran}

\section{a. Analisis terhadap Stabilitas}

Nilai stabilitas adalah 1190,98 kg - 1545,08 kg saat menggunakan aspal 5\% - 7\% untuk lapisan Asphalt Concrete - Binder Course. Seluruh nilai stabilitas lapisan Asphalt Concrete - Binder Course memenuhi persyaratan umum Kementerian Pekerjaan Umum 2018. Berdasarkan Gambar 2 dapat dilihat bahwa penggunaan aspal dalam jumlah besar pada campuran lapisan Asphalt Concrete - Binder Course menghasilkan permukaan agregat yang lebih baik tertutup aspal, yang menghasilkan daya rekat agregat yang lebih kuat dan mengakibatkan berkurangnya flow. Namun jika kandungan aspal terus meningkat, rongga antara agregat berkurang dan daya rekat antara agregat selama pemadatan berkurang, yang mengurangi kekuatan campuran dan akibatnya meningkatkan flow-nya. 


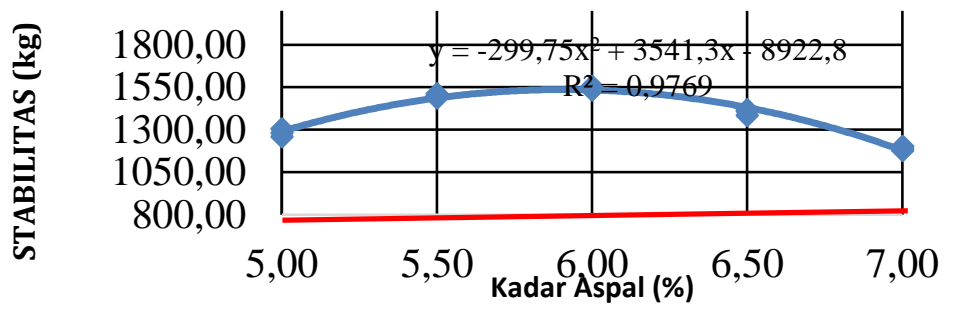

Gambar 2. Hubungan KA terhadap stabilitas

\section{b. Analisa terhadap VIM (Void in Mix)}

Penggunaan kadar aspal 5\% - 7\%. Campuran AC-BC diperoleh nilai VIM antara 4,92\%-3,02\%. Maka semua campuran AC-BC memenuhi persyaratan. Berdasarkan Gambar 3 maka dapat diketahui penggunaan kadar aspal yang banyak akan mengakibatkan VIM menjadi kecil dan apabila kadar aspal yang digunakan sedikit maka VIM akan menjadi besar.

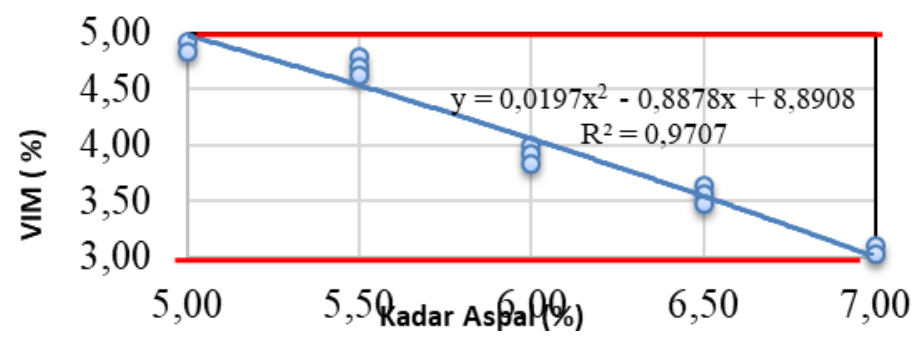

Gambar 3. Hubungan KA terhadap VIM AC - BC

\section{c. Analisa terhadap Flow}

Saat menggunakan kadar aspal 5\% - 7\% dalam campuran Asphalt Concrete - Binder Course, nilai flow adalah 3,85 mm - 2,35 mm. Semua nilai flow kadar aspal 5\% dan 7\% untuk campuran Asphalt Concrete Binder Course semuanya memenuhi Spesifikasi Umum Departemen Pekerjaan Umum Divisi 6. Gambar 4 menunjukkan bahwa rendahnya penggunaan aspal dalam campuran aspal mengakibatkan berkurangnya ikatan antara agregat, sehingga menghasilkan kelelehan yang lebih tinggi. Namun, jika penggunaan aspal meningkat, ikatan antara agregat campuran menjadi lebih kuat, dan titik leleh campuran menurun.

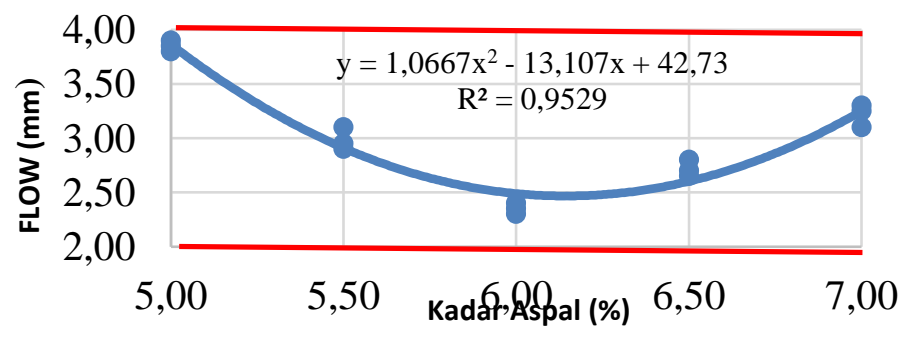

Gambar 4. Hubungan KA dan flow

\section{d. Analisa terhadap VMA (Void in Mineral Aggregate)}

Penggunaan kadar aspal 5\% sampai 7\% pada campuran Asphalt Concrete - Binder Course menghasilkan nilai VMA $14,59 \%$ sampai $17,82 \%$. Semua kadar aspal memenuhi persyaratan umum Dinas Pekerjaan Umum 2018, Divisi 6. Aspal dalam jumlah besar saat dicampur mempengaruhi nilai VMA campuran karena 
fungsi aspal (aspal efektif) selain sebagai penutup ini juga mengisi celah antara agregat dan partikel agregat. Dari Gambar 5 terlihat bahwa penggunaan aspal yang lebih banyak mengisi rongga-rongga pada agregat, memperbesar ukuran agregat yang terisi aspal dan meningkatkan nilai VMA.

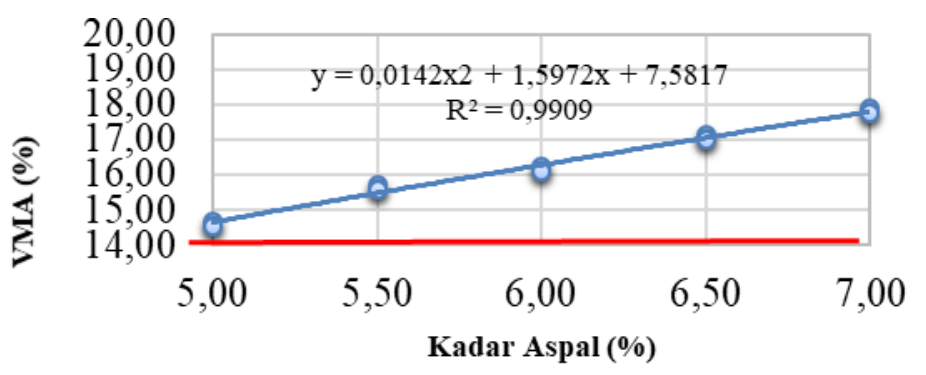

Gambar 5. Hubungan KA terhadap VMA

\section{e. Analisa terhadap VFB (Void Filled with Bitumen)}

Jika kadar aspal campuran Asphalt Concrete - Binder Course adalah 5\% sampai 7\%, maka didapatkan nilai VFB antara 66,29\% sampai 83,07\%. Nilai VFB tersebut sesuai dengan Departemen Pekerjaan Umum Tahun 2018 Divisi 6. Berdasarkan Gambar 6, terlihat bahwa bila digunakan aspal yang sedikit maka VFB berkurang, VFB meningkat bila digunakan aspal dengan kadar tinggi. Dimana aspal pada campuran akan mengisi semua rongga campuran pada agregat.

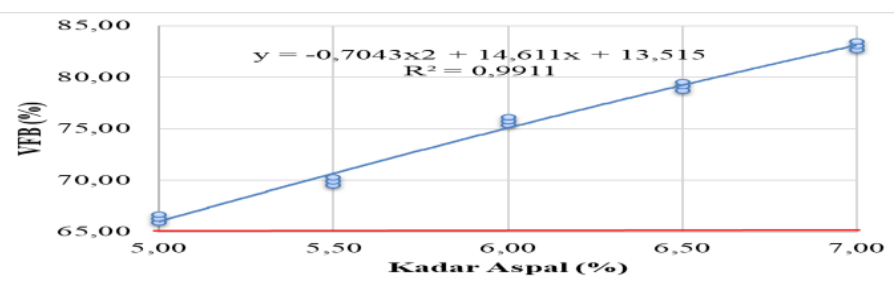

Gambar 6. Hubungan KA dan VFB

\section{f. Penentuan KAO}

Kadar aspaI optimum untuk campuran Asphalt Concrete - Binder Course kadar optimumnya ialah campuran yang memiliki niIai kekuatan campuran/stabilitas yang paling besar yaitu pada kadar aspal 6,00\% dan campuran merupakan campuran yang memenuhi standar spesifikasi.

\section{g. Hasil Stabilitas Marshall Sisa (SMS)}

MeIaIui pengujian Marshall Immersion diperoIeh hasil Stabilitas Marshall Sisa sebesar 92,59 \% dengan kadar aspaI 6,00\%. NiIai Stabilitas Marshall Sisa ini teIah memenuhi Spesifikasi Umum Bina Marga 2018 dengan nilai minimal 90\%. Dengan demikian agregat Sungai Apanang dapat digunkan untuk campuran Asphalt Concrete - Binder Course sebab tahan terhadap perendaman.

\section{KESIMPULAN}

Berdasarkan hasil penelitian, dapat ditarik kesimpulan sebagai berikut:

1. Hasil Karakteristik Sungai Apanang Kabupaten Soppeng Aspal minyak penetrasi 60/70 dan berat jenis filler (semen) untuk campuran Asphalt Concrete - Binder Course memenuhi standar bina marga 2018.

2. Komposisi campuran Asphalt Concrete - Binder Course yang digunakan adalah agregat kasar 42,82\%, agregat halus 45,73\%, filler 5,45\% dengan kadar aspal optimum $6 \%$.

3. Berdasarkan hasil uji Marshall Konvensional diperoleh nilai VIM, VMA, stabilitas, flow dan VFB 
memenuhi standar yang dikeluarkan oleh Dirjen Bina Marga. Sedangkan hasil pengujian Stabilitas Marshall Sisa pada campuran Asphalt Concrete - Binder Course yang menggunakan agregat Sungai Apanang Kabupaten Soppeng memenuhi standar Bina Marga 2018, yaitu 92,59\% > $90 \%$.

\section{DAFTAR PUSTAKA}

[1] S. Sukirman, Beton Aspal Campuran Panas, Edisi Kedua. Jakarta: Yayasan Obor Indonesia, 2013.

[2] C. Kamba, "Agregat dari Material Lokal," dalam Pemanfaatan Material Alternatif (Sebagai Bahan Penyusun Konstruksi), Makassar: CV. Tohar Media, 2021, hlm. 35-46.

[3] Direkorat Jenderal Bina Marga, Spesifikasi Umum Bina Marga 2018 untuk Pekerjaan Konstruksi Jalan dan Jembatan Divisi 6. Jakarta: Kementerian Pekerjaan Umum dan Perumahan Rakyat, 2018.

[4] R. Rachman, "The Effect of Immersion and Humidification Toward Performance of Hot Rolled Asphalt Mixture," Int. J. Appl. Eng. Res., vol. 15, no. 5, hlm. 503-509, 2020.

[5] M. Palebangan, R. Mangontan, dan Alpius, "Pengujian Karakteristik Campuran Laston Lapisan Antara Menggunakan Batu Sungai Pucak Kabupaten Maros,” Paulus Civ. Eng. J., vol. 3, no. 3, hlm. 431-440, 2021.

[6] N. Sambo, R. Rachman, dan Alpius, "Pemanfaatan Limbah Styrofoam Sebagai Bahan Tambah Campuran ACBC Yang Menggunakan Sungai Bittuang,” Paulus Civ. Eng. J., vol. 3, no. 3, hlm. 330-340, 2021.

[7] R. Rachman, "Pemanfaatan Batu Gunung Bottomale Toraja Utara sebagai Campuran Laston," J. Tek. Sipil Dan Teknol., vol. 6, no. 1, hlm. 20-30, 2020.

[8] G. P. Palimbunga, R. Rachman, dan Alpius, "Penggunaan Agregat Sungai Batu Tiakka' dalam Campuran ACBC," Paulus Civ. Eng. J., vol. 2, no. 2, hlm. 112-118, 2020.

[9] Deamayes, Alpius, dan C. Kamba, "Pemanfaatan Batu Sungai Melli Kecamatan Baebunta Kabupaten Luwu Utara Dalam Campuran AC-WC,” Paulus Civ. Eng. J., vol. 3, no. 1, hlm. 85-91, 2021.

[10] A. R. Seppo, R. Rachman, dan N. Ali, "Variasi Suhu Pemadatan Campuran AC-WC Menggunakan Batu Sungai Balusu Kabupaten Toraja Utara," J. Matriks Tek. Sipil, vol. 9, no. 1, hlm. 23-31, 2021, doi: https://doi.org/10.20961/mateksi.v9i1.49248.

[11] N. A. Salmon, Alpius, dan C. Kamba, "Pemanfaatan Batu Gunung Posi’padang Balla Kabupaten Mamasa Sebagai Campuran AC-BC," Paulus Civ. Eng. J., vol. 2, no. 2, hlm. 77-84, 2020. 